\title{
Micro-sized carbon with dimple patterns prepared using an electro-spray method
}

\author{
Mi-Seon Park and Young-Seak Lee* \\ Department of Applied Chemistry and Biological Engineering, Chungnam National University, Daejeon 305-764, Korea
}

\section{Article Info}

Received 2 November 2014

Accepted 15 January 2015

*Corresponding Author

E-mail: youngslee@cnu.ac.kr

Tel: $+82-42-821-7007$

\section{Open Access}

DOI: http://dx.doi.org/

10.5714/CL.2015.16.3.215

This is an Open Access article distributed under the terms of the Creative Commons Attribution Non-Commercial License (http://creativecommons.org/licenses/ by-nc/3.0/) which permits unrestricted non-commercial use, distribution, and reproduction in any medium, provided the original work is properly cited.

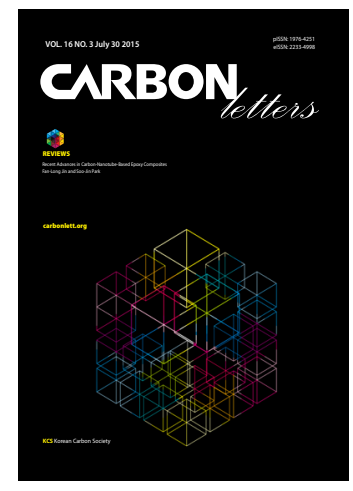

http://carbonlett.org

pISSN: 1976-4251

elSSN: 2233-4998

Copyright $\odot$ Korean Carbon Society

\begin{abstract}
Carbon micro particles with dimple patterns were produced by electro-spraying a solution of pitch in tetrahydrofuran. Particle formation depended on separation in an electrical field and volatilization of the solvent. More than $80 \%$ of the obtained carbon exhibited an average particle size of less than $50 \mu \mathrm{m}$. X-ray diffraction analysis suggests that the carbon with dimple patterns has increased crystallinity after heat treatment.
\end{abstract}

Key words: electro-spraying, pitch, micro-sized carbon

\section{Introduction}

The application of electrospinning for the formation of various polymeric shapes has been widely reported in recent years [1-3]. Electrospraying is a useful process for production of droplets that are highly charged to prevent aggregation $[4,5]$. This process can be used with a diverse selection of polymers, and droplets can be controlled according to flow rate, tip-tocollector distance (TCD), and concentration of the polymer solution [6]. Electrospraying has been actively researched in many industries because of its potential applications for microencapsulation [7], electroemulsification [8], and fine powder production [9] from a polymer solution. Recently, microscale and nanoscale particles obtained using the electrospraying technique have been used in biochips, biosensors, and drug delivery systems due to their high specific surface area [10]. The materials for biosensors need to have good electrical conductivity because they react to electrical signals. Pitch, which is obtained from a heattreatment process for coal and petroleum, is a mixture of aromatic compounds of various molecular weights. Pitch is applied to different applications depending on the composition of the aromatic compounds and its softening point. In this study, the electrospray technique was used to produce a pitch powder with a unique shape that differs from other polymers described in the literature.

\section{Experimental}

Pitch (HPCP-60, SP $296^{\circ} \mathrm{C}$, Hanwha Chemical, Korea) was purified with dimethylformamide (DMF, $99.8 \%, \mathrm{mp} 152^{\circ} \mathrm{C}$, Aldrich) to obtain a high molecular weight pitch precursor that was favorable for orientation during heat-treatment. The purified pitch was dissolved in tetrahydrofuran (THF, $\mathrm{mp} 66^{\circ} \mathrm{C}$, J.T. Baker), and the solution was vigorously stirred at $55^{\circ} \mathrm{C}$. After being poured into a $30 \mathrm{~mL}$ syringe, the prepared pitch solution was electrically sprayed using electrospraying equipment.

The experiment was conducted by changing the weight percent of the pitch solution, the applied voltage, and the flow rate. In the first experiment, the weight percent of the pitch solution was $5,10,15,20$, or $25 \mathrm{wt} \%$. However, $25 \mathrm{wt} \%$ was not electro-sprayed. These solutions were experimentally sprayed at a fixed voltage of $22 \mathrm{kV}$, a flow rate of $2.0 \mathrm{~mL} / \mathrm{h}$, a TCD of $10 \mathrm{~cm}$, a rotational velocity of 800-850 rpm, and through an 18 gauge (18G) needle. 
In the second experiment, the applied voltage was $17,20,22$, or $25 \mathrm{kV}$. The solution concentration was fixed at $15 \mathrm{wt} \%$; the other conditions were similar to those in the first experiment. In the third experiment, the flow rate was $0.5,0.7,1.0,1.3,1.5$, or 2.0 $\mathrm{mL} / \mathrm{h}$. The solution concentration was fixed at $15 \mathrm{wt} \%$, and the other conditions were similar to those in the first experiment.

The pitch powder prepared from $15 \mathrm{wt} \%$ pitch solution was heated for stabilization and carbonization at $300^{\circ} \mathrm{C}$ at a rate of $1^{\circ} \mathrm{C} /$ min under air atmosphere in a convection oven, and then at $1050^{\circ} \mathrm{C}$ at a rate of $5^{\circ} \mathrm{C} / \mathrm{min}$ under a $100 \mathrm{cc} / \mathrm{min}$ flow of nitrogen gas, respectively. In both cases, the sample was maintained at the set-point temperature for $1 \mathrm{~h}$.

Field-emission scanning electron microscopy (FESEM, Hitachi, S-4700, the Korea Basic Science Institute [KBSI], Jeonju Center) was used to investigate the shape of the electro-sprayed pitch powder and that of the pitch powder after heat-treatment. The size of the electro-sprayed pitch powder was examined using a particle size analyzer (HEROS, Sympatec GmbH, Germany). The crystal structure of the heat-treated pitch was also analyzed by X-ray diffraction diffractometer (XRD, D8 DISCOVER, Bruker AXS, Germany). The X-ray source was $\mathrm{Cu}$ $\mathrm{K} \alpha$ radiation generated by a $3-\mathrm{kW} \mathrm{X}$-ray tube with $\mathrm{Cu}$ target. The diffractometer was used over the $2 \theta$ range of $10^{\circ}-80^{\circ}$ with a resolution below $0.003^{\circ} / \mathrm{min}$ and a detection rate of $10^{-6} \mathrm{~s}$.

\section{Results and Discussion}

Changes in particle shape were observed in association with changes in the solution conditions. Fig. 1 shows changes in particle size depending on the concentration of the pitch solution. As the concentration of the pitch solution increased, the particles of electro-sprayed pitch powder became larger. The 25 wt $\%$ pitch solution could not be electro-sprayed because of its high density. This resulted from its low solubility in THF at this concentration. This result is believed to be because the increased concentration of the pitch solution requires a stronger electrical field to separate the solution into droplets at the tip, at a constant voltage [11]. Therefore, the solution could not be divided into distinct particles.

Fig. 1e shows the pitch powder on the substrate. The shape of the pitch powder obtained was similar to that of popcorn. This phenomenon was caused by the increase in concentration of the pitch near the electro-sprayed powder, which likely increased the Peclet number $(\mathrm{Pe})[12,13]$. The Pe is a measure of the relative importance of advection to diffusion. The more important advection is, the higher the value of Pe will become, indicating increased particle displacement. As the concentration of the pitch powder surface increased, a thin crust was formed on the surface of the pitch powder. As more solvent vaporized, the crust thickness increased to form hollow particles, and then collapsed to form popcorn particles $[14,15]$.

Fig. 1f is an enlarged image of the wall surface of the pitch powder. The surface wall displayed a dimple pattern like that of a golf ball because of evaporation of the solvent (i.e., THF) during the electro-spraying process. THF, which is a highly volatile solvent at room temperature, removed a small amount of pitch while volatilizing. The SEM images show that all particles were

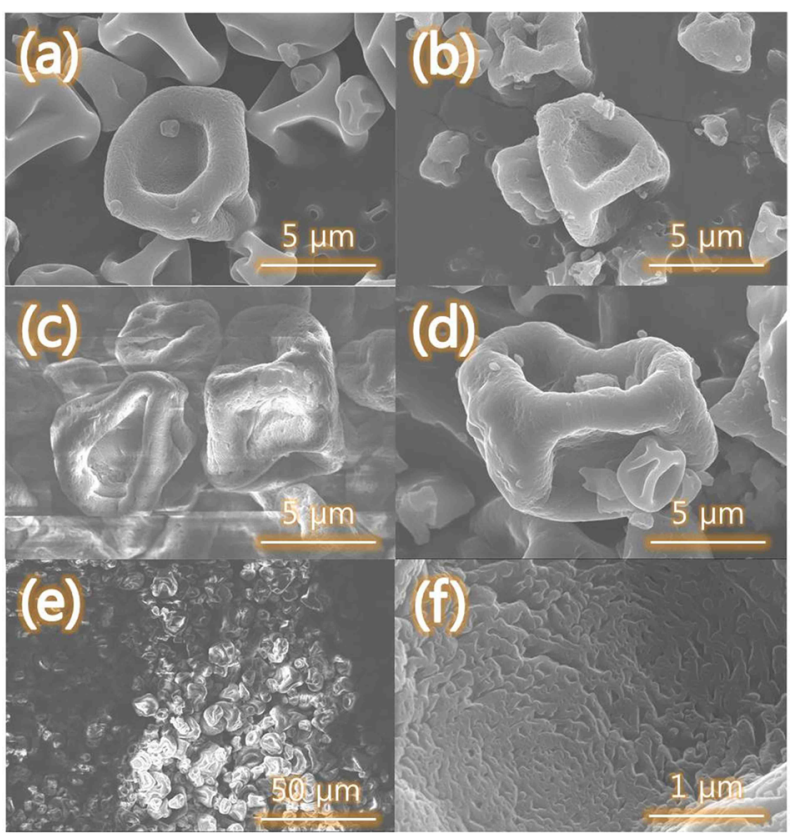

Fig. 1. Pitch particles produced by electro-spraying with (a) $5 \mathrm{wt} \%$, (b) $10 \mathrm{wt} \%$, (c) $15 \mathrm{wt} \%$, and (d) $20 \mathrm{wt} \%$ pitch solution; (e) whole particles and (f) surface wall of the obtained pitch powder at $15 \mathrm{wt} \%$.

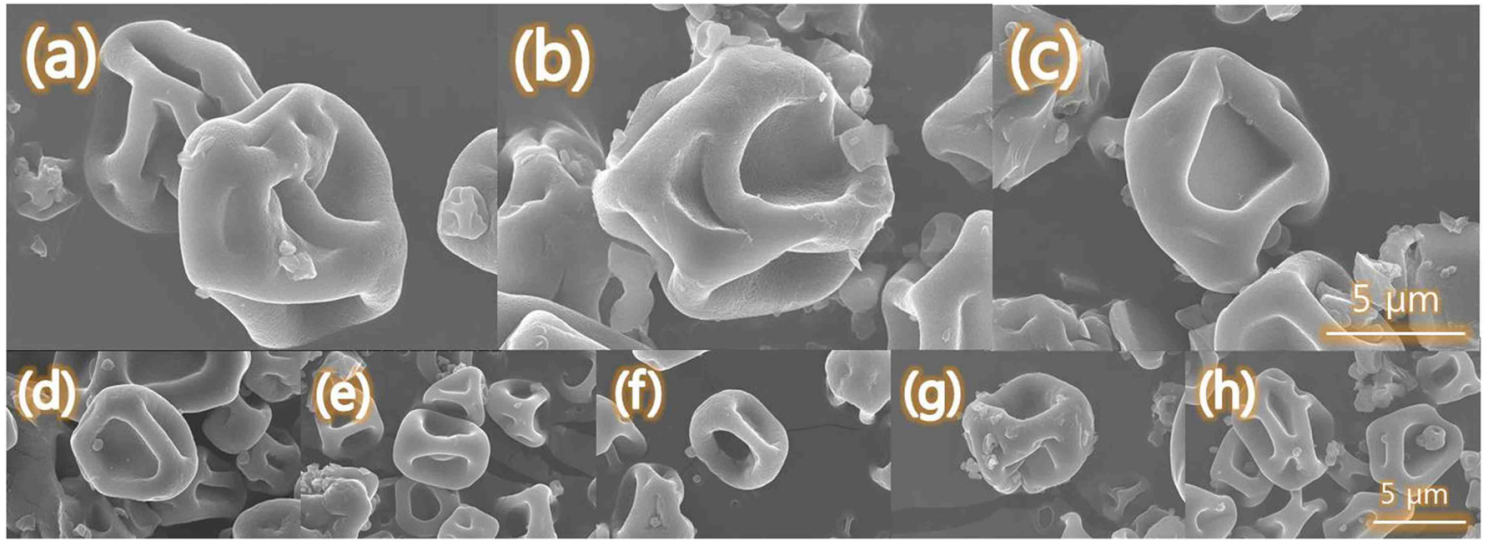

Fig. 2. Pitch particles produced by electro-spraying at (a) $17 \mathrm{kV}$, (b) $20 \mathrm{kV}$, (c) $25 \mathrm{kV}$, (d) $0.7 \mathrm{~mL} / \mathrm{h}$, (e) $1.0 \mathrm{~mL} / \mathrm{h}$, (f) $1.3 \mathrm{~mL} / \mathrm{h}$, (g) $1.5 \mathrm{~mL} / \mathrm{h}$, and (h) $2.0 \mathrm{~mL} / \mathrm{h}$. 


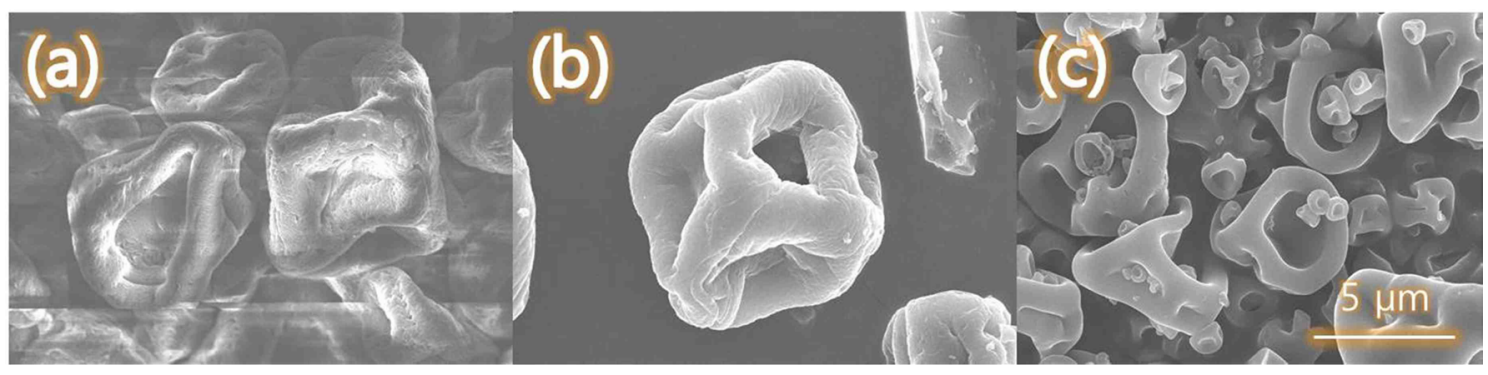

Fig. 3. Electro-sprayed pitch particles after (a) electro-spraying, (b) stabilization, and (c) carbonization.

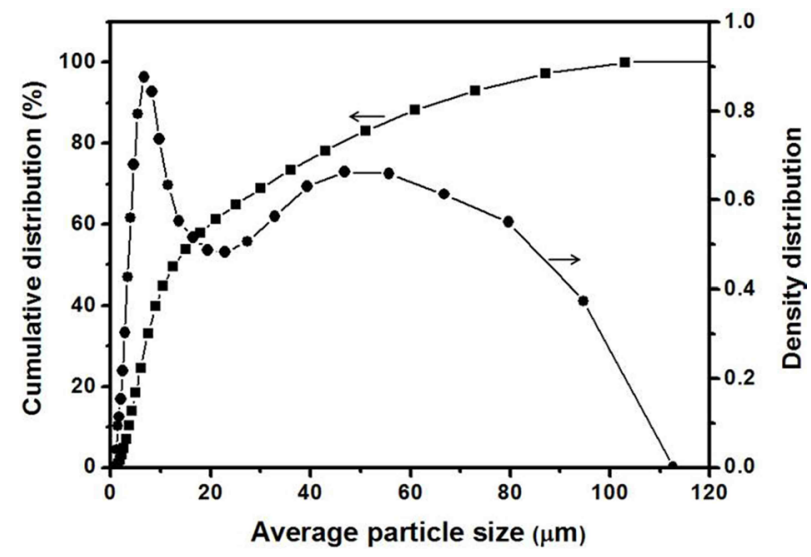

Fig. 4. Electro-sprayed pitch particle size diagram.

separated from each other, which indicate a low surface tension force in THF acting on the pitch particles during drying [16,17].

Shape changes due to changes in the applied voltage and flow rate were also observed. The obtained pitch powder was insignificantly changed by varying the applied voltage and flow rate during the electro-spraying process as shown Fig. 2. However, the particle morphologies were shown to vary with increasing applied voltage and decreasing flow rate, both of which resulted in reduced particle size. However, the size of the pitch obtained was similar on the whole. The pitch solution apparently experienced stable fluctuations between dripping and jet modes, which differs markedly from the behavior exhibited by other polymeric solutions $[13,18]$.

The size and structural properties of the resulting carbon were also investigated. Fig. 3 shows the shape of the pitch particles after electro-spraying (ES), stabilization (ESS), and carbonization (ESSC) processes. The electro-sprayed pitch powder exhibited a dimple pattern on its surface; however, this pattern disappeared after heat-treatments. This is likely because the carbon hexagonal plane was rearranged by the heat-treatment. The stabilized pitch powder exhibited a cage structure, whereas the carbonized pitch powder exhibited a smooth surface. Fig. 4 shows the size of the pitch particles obtained using the spraying conditions of $15 \mathrm{wt} \%$, voltage $22 \mathrm{kV}$, flow rate $2.0 \mathrm{~mL} / \mathrm{h}$, TCD of $10 \mathrm{~cm}$, rotational velocity of $800-850 \mathrm{rev} / \mathrm{min}$, and needle size of $18 \mathrm{G}$. In Fig. 4, the cumulative distribution demonstrates that more than $80 \%$ of the electro-sprayed pitch particles exhibited a size smaller than $50 \mu \mathrm{m}$. This result indicates that ES does not produce pitch particles of uniform size. The particle size obtained

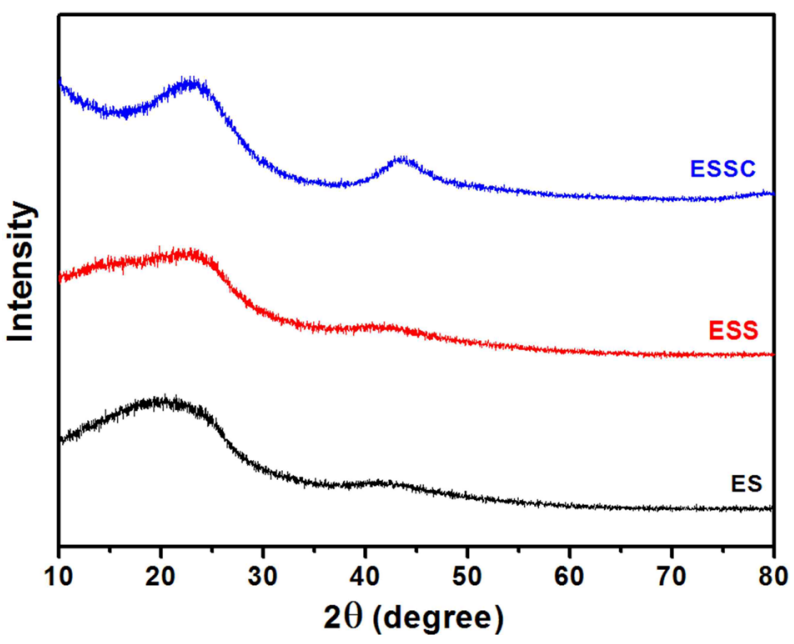

Fig. 5. X-ray diffraction patterns of electro-sprayed pitch after heattreatment. ES: electro-spraying, ESS: electro-spraying stabilization, ESSC: electro-spraying carbonization.

after ES depends on the pitch molecular weight dissolved in the solvent, here THF, under constant applied voltage. Fig. 5 shows the crystallinity of the pitch powder after ES, ESS, and ESSC, respectively. ESSC showed amorphous peaks at approximately $23^{\circ}$ and $43^{\circ}$, compared to the patterns of ES and ESS. Originally, broad XRD peaks for amorphous carbon materials typically appear around $\sim 26^{\circ}$ and $\sim 43^{\circ}$, which contributed to reflection from the (llll $\left.0 \begin{array}{lll}0 & 2\end{array}\right)$ and $\left(\begin{array}{lll}1 & 0 & 1\end{array}\right)$ crystal planes, respectively [19]. The appearance of amorphous peaks indicated that crystallites for a specific crystal plane were arranged during the heat-treatment.

\section{Conclusions}

Pitch powder with a dimple pattern was obtained via an ES process under various solution concentrations, applied voltages, and flow rates. The resulting pitch powder was not affected by these variables because the pitch solution was more stable than other polymer solutions. The particle sizes of the obtained powder were primarily smaller than $50 \mu \mathrm{m}$ in diameter. After stabilization, a cage structure appeared in the middle of the pitch powder, and after carbonization, amorphous peaks of the pitch powder increased slightly, without a significant change of form. These findings demonstrate that ES pitch powder solution created a new form of carbon micro particles. 


\section{References}

[1] Zamani M, Prabhakaran MP, Thian ES, Ramakrishna S. Protein encapsulated core-shell structured particles prepared by coaxial electrospraying: investigation on material and processing variables. Int J Pharm, 473, 134 (2014). http://dx.doi.org/10.1016/j. ijpharm.2014.07.006.

[2] Saallah S, Naim MN, Mokhtar MN, Bakar NFA, Gen M, Lenggoro IW. Transformation of cyclodextrin glucanotransferase (CGTase) fromaqueous suspension to fine solid particles via electrospraying. Enzyme Microb Technol, 64-65, 52 (2014). http://dx.doi. org/10.1016/j.enzmictec.2014.06.002.

[3] Bohr A, Yang M, Baldursdóttir S, Kristensen J, Dyas M, Stride E, Edirisinghe M. Particle formation and characteristics of Celecoxibloaded poly(lactic-co-glycolic acid) microparticles prepared in different solvents using electrospraying. Polymer, 53, 3220 (2012). http://dx.doi.org/10.1016/j.polymer.2012.05.002.

[4] Jaworek A, Sobczyk AT. Electrospraying route to nanotechnology: an overview. J Electrostat, 66, 197 (2008). http://dx.doi. org/10.1016/j.elstat.2007.10.001.

[5] Kim GH, Park JH, Han H. Production of microsized PMMA droplets using electrospraying with various auxiliary fields. J Colloid Interface Sci, 299, 593 (2006). http://dx.doi.org/10.1016/j. jcis.2006.02.054.

[6] Jaworek A. Micro- and nanoparticle production by electrospraying. Powder Technol, 176, 18 (2007). http://dx.doi.org/10.1016/j. powtec.2007.01.035.

[7] Bock N, Dargaville TR, Woodruff MA. Controlling microencapsulation and release of micronized proteins using poly(ethylene glycol) and electrospraying. Eur J Pharm Biopharm, 87, 366 (2014). http://dx.doi.org/10.1016/j.ejpb.2014.03.008

[8] Khan MKI, Maan AA, Schutyser M, Schroën K, Boom R. Electrospraying of water in oil emulsions for thin film coating. J Food Eng, 119, 776 (2013). http://dx.doi.org/10.1016/j.jfoodeng.2013.05.027.

[9] Valvo M, Lafont U, Munao D, Kelder EM. Electrospraying-assisted synthesis of tin nanoparticles for Li-ion battery electrodes. J Power Sources, 189, 297 (2009). http://dx.doi.org/10.1016/j.jpow- sour.2008.09.019.

[10] Oh HN, Ko JY, Jeong YH. Study on the site modulation of polystyrene micro/nanoparticles in electrospraying. Proceedings of the Korean Society for Precision Engineering Spring Conference, 331 (October 2012)

[11] Moghadam H, Samimi M, Samimi A, Khorram M. Electro-spray of high viscous liquids for producing mono-sized spherical alginate beads. Particuology, 6, 271 (2008). http://dx.doi.org/10.1016/j.partic.2008.04.005

[12] Coutelieris FA, Kainourgiakis ME, Stubos AK. Low Peclet mass transport in assemblages of spherical particles for two different adsorption mechanisms. J Colloid Interface Sci, 264, 20 (2003). http://dx.doi.org/10.1016/S0021-9797(03)00309-6.

[13] Kishore N, Chhabra RP, Eswaran V. Mass transfer from ensembles of Newtonian fluid spheres at moderate Reynolds and Peclet numbers. Chem Eng Res Des, 85, 1203 (2007). http://dx.doi. org $/ 10.1205 /$ cherd06250.

[14] Fiegel J, Garcia-Contreras L, Elbert K, Hickey A, Edwards D. Dry powder aerosols for multi-drug resistant tuberculosis (Mdr- $\mathrm{Tb}$ ) treatment. Proceedings of the 2005 AIChE Annual Meeting, Cincinnati, OH, 297b (2005).

[15] Yao J, Lim LK, Xie J, Hua J, Wang CH. Characterization of electrospraying process for polymeric particle fabrication. J Aerosol Sci, 39, 987 (2008). http://dx.doi.org/10.1016/j.jaerosci.2008.07.003.

[16] Wu Y, Clark RL. Controllable porous polymer particles generated by electrospraying. J Colloid Interface Sci, 310, 529 (2007). http:// dx.doi.org/10.1016/j.jcis.2007.02.023.

[17] Park CH, Lee J. Electrosprayed polymer particles: effect of the solvent properties. J Appl Polym Sci, 114, 430 (2009). http://dx.doi org/10.1002/app.30498.

[18] Zhang X, Kobayashi I, Uemura K, Nakajima M. Direct observation and characterization of the generation of organic solven droplets with and without triglyceride oil by electrospraying. Colloids Surf A, 436, 937 (2013). http://dx.doi.org/10.1016/j.colsurfa.2013.07.032.

[19] Li ZQ, Lu CJ, Xia ZP, Zhou Y, Luo Z. X-ray diffraction patterns of graphite and turbostratic carbon. Carbon, 45, 1686 (2007). http:// dx.doi.org/10.1016/j.carbon.2007.03.038 